\title{
Teaching Management System-based Undergraduate Academic Early Warning Helping System Developed
}

\author{
Xiongwei Shen, Yihua lu,Meihua Shi,Hanfeng wang, Liang wu \\ Donghua University, Academic Affairs Shanghai 201620 China \\ E-mail:tigersxw@dhu.edu.cn
}

Keywords: Learning difficulties, early warning, to extend the school year, coordinators

\begin{abstract}
In this paper, the the existing undergraduate educational management system, data, design and development of learning difficulties earl y warning helping system based on a set of Undergraduate Teaching Management System. Through the set warnin g threshold conditions, the warning helping system sieve screen out students with learning difficu lties, and to take precautions targeted, multi-channel communication and collabor ation between schools, teachers, students and parents to help students to over come the difficulties, the successful completion of their stud ies. In-depth analysis of the data in the Senate system, using the sy stem to m onitor student data in accordance with a pre-set warning threshold, analysis, feedback, and take the appropriate corrective measures, and ultimately form a joint force to prevent a deviation from the normal college students' academic track.
\end{abstract}

\section{Introduction}

In order to fulfill the requirem ent of our country' s rapid econom ic development on talen ted people's knowledge structure, overall capabiliti es, and competency, $\mathrm{m}$ any higher educational institutes in our country have set their goals to cultivate well talented and innovative s tudents, and, therefore, have explored and practiced som e reforms on the training $\mathrm{m}$ odel and teaching management system. They build a credit teach ing management system, based o $n$ the system of selecting classes and the guarantee of $\mathrm{m}$ odern educational management, in order to propel the modernization of the educational $\mathrm{m}$ anagement, and fulfill the im perative requirement of our country's economic, scientific, and social development.

Take Donghua University as an example. The uni versity reformed the credit based system in 2002. The institute implemented a well rounded educati on with the pos sibility to change focuses. The institute also prop elled changes on the heu ristic research based way of teaching, in order to arise the awareness of innovation and find potential. The implementation of the credit based system has given students more free selections on courses, developed a flexible learning system, prosecuted a flexible time limit of study, and improved the act iveness and willingness to study. The system encourages the personalized development of students. With the instructions of the advisors, students select the courses, time, and instructors freely, arrange the progress of the study freely, and have personalized development. The ultim ate goal of th e reform is to cultivate well rounded and talented people that have practical experience, are innovative and collaborative, and can fulfill the requirement of the modernization of socialism.

Meanwhile, with the full implementation of the credit based system, there are new problem s as well. While schools are giving students plenty of freedom on their studies, they are $m$ aking the students within the sam e major have different progress, which causes difficulties for the management team to accurately $\mathrm{m}$ anage the co mpletion of study within a certain tim e period, especially on students with difficulties on their studies. Because of traum atic events, family misfortune, obsess on the internet, health co nditions, and so on, thes e students cannot study regularly through their own efforts. This pheno menon is getting serious with the popularization of higher education and expansion of the educational scope. These students with difficulties in their studies are usually unable to finish ed the required credit hours within four years and have to extend their studies. Moreover, some even cannot finished within an extended study period. Faced with the increasing number of students who cannot finish their studies on time, the education $m$ anagement team thinks that there will be severe consequences, if this phenomenon is not prevented. 


\section{The current situation of the precautions system for students with learning difficulties in higher education in our country}

Literature[1] points out that the $\mathrm{m}$ ain method to implement the "process management" mode on students with learning difficulties are 1) establish a list of students who need "process management" care according to grades and e motional conditions; 2) know more about the overall situation of the students and make plans to help; 3 ) keep record s of the students who need "process $m$ anagement" care and provide different care to different student s; 4) make some achievements. Chen and some other people[2] point out that we sho uld differentiate all types of students with learning difficulties and then study each type, take school and instructors into consideration when studying the cases of students with learning difficulties, sort all kinds of learning difficulties that fit the overall situation of our country, and develop theories on le arning difficulties. W ang, Xue, Gao, and Shen [3][4] emphasized their analy sis on th e reasons of ha ving learning difficulties, and som e author[3] proposes a tentative plan on building the precauti ons system and categorical precautions system. Sun proposes a precautions model based on campus internet. This model is centered at students, and integrates the traditional campus info management system and the inf rastructure system into a digital campus learning precautions system that meets the needs of the care for learning. The system includes precautions on attendance, completion of assignments, completion of courses in major, the cultivation plan on study, and the process of courses. Ding $m$ akes several strategies on the optimization of the management of students with learning difficulties in higher education, which include completion of the credit system record management, improvement of the efficacy of students with learning difficulties, and the reinforcement of communication between departments.

In sum, the people $\mathrm{h}$ as been aware that the ex pansion in the adm ission of students in higher educational institutes in our $\mathrm{c}$ ountry has led to the expansion of the number of students $\mathrm{w}$ ith learning difficulties. We have explored the establishment of a system that provides care for students with learning difficulties, a dopted some corresponding strate gies on $\mathrm{m}$ anagement, and also proposed the respective system that provides care fo $r$ students with learning difficulties. However, there is still some inadequacy in the whole picture. First, the management of students with learning difficulties is still at the be ginning. Some school's management systems still focuses on th $\mathrm{e}$ consequence and its managem ent, which m eans the problems of students burst out at their graduation, and the monitoring and managing on the process is inadequate; Som e schools studied the reasons for learning difficulties, and use the strategies and policies to help students establish a correct outlook of life encouraging students into an studying attitude. But they still lack the overall research and practice on the prevention of learning difficulties. Second, there is a lack of special academic monitoring precau tions system. Though so me schools $\mathrm{h}$ ave established precautions system, the management mode is still by manual. Literature[5] points out that although the internet based learning precautions system can be established, the model involves so many aspects, such as attendance, completion, and so on. Th is is still difficult to be adopted in digitalized cam pus, and some operations with $\mathrm{d}$ ata tables still need to be done $\mathrm{m}$ anually. This is not so effi cient, and the effect on monitoring and managing the completion of study has no guarantee.

\section{The structure and function of the system}

This paper uses the existing data from the undergraduate Senate management system and has designed a precau tions care system based on cred it management system for undergrads with learning difficulties. This system will $\mathrm{m}$ ainly solve the potential academic problems, point out problems promptly, inform students and their parent $s$ the long term adverse effects, and take the corresponding prevention strategies. This system is a platform of communication that can help students complete their study successfully th rough the comm unication and cooperation of the schools, the instructors, the students, and their pare nts. Using this platf orm to further analyze the data in the Senate system, monitoring the data, and analyzing feedbacks of the data according to the designed warning threshold, we can eventually collaborate to prevent college students from having learning difficulties. The learning difficulty precautions and care sy stem is based on funda mental data management, student academic precautions management, extension of studying period system, student care platform, and online attendance check. The functions of its sp ecific modules are as 
follow:

A. Fundamental Data Management.

The establishment of the academ ic precautions care system should first solve the $p$ roblems of collecting and organizing relevant data of the students so that the data after the analysis can become evidence of each departm ent on making the $s$ trategies of precau tions and care. The learning difficulty precautions care system share such rele vant info with the cam pus credit management system as the demographic data, grades of each semester, honors, and penalties. This guarantees the data supply of the precautions system for students with learning difficulties.

B. Student Academic Precautions Management.

This is a $\mathrm{m}$ anagement module developed fo $\mathrm{r}$ undergrads with learning difficulties from freshman level to senior level. The module includes:

1) The value of academ ic precaution. There are many regulations on students' academic management, and each regulation has its own in dex in the student manual. The computer gives the corresponding treatment on the extent to which the behavior or c onsequence of the student lead. The system has set up four levels of academ ic preca ution according to the cam pus roll management. The 4 levels are yellow card warni ng; resignation warning; probation; imm ediate resignation.

2) Setting up academ ic precaution. The sys tem will select all the students who fulfill the requirement according to pre-established value, ( for example, students who gain less than 15 hours in one semester), and set those students into who need precaution this semester.

3) The database of stud ents who need precautions. The database separate studen ts into four data table according to the pre-established value. Then the system put the stud ents into th eir corresponding precautions database according to the maximum number of precautions given. This guarantees that every student appear only once in the system.

4) Evaluation on students who have precautions. This evaluation mainly analyzes the data on the students who have got precautions in history, in order to track their progress. Through analyzing the data on these students, we can change and comple te the way of our thinking and the method we use on helping the students, and thus, lowing the number of students that need these care.

C. Management Of students Who Extend Academic Years.

This module mainly focuses on seniors who cannot graduate on tim e. These students usually cannot graduate on time because of the failure of several courses, and the management on these students are still loose. So enhancing the management on these students is one of the $m$ ain points in the precautions care system. This module mainly contains:

1) The requirement on major courses. The system displays the graduation checklist in tables, so that students can look up easily. St udents can adjust their study plan s according to their current credits earned.

2) Management on students who need extension. Th e system automatically selects the names of the students that are set into extension in the undergraduate Senate system and displays the students' ID number, class, name, advisor, major, GPA, attendance, registration, and other relevant info to the staff. The st aff click "ID num ber", and the origin al transcript of the students app ears. Click on "name", and demographic info appears; click on "class" and appears the credits earned.

D. Student Care Management.

This module mainly enhance the communication between school, parents, and students and help to take record of relevant info. This module includes:

The employment of the coordinators. Higher e ducation precaution and care system needs the collaboration of school, parents, and students and will contain different de partment and relevant faculty. Combined with the uniqueness of the institute itself, the people that involve in the campus precaution and care are faculty, adv isors, senators, secretaries, psychologists, and class pres idents. Because of this, we need an coordinato $r$ to en sure the co mmunication and avoid prevarication. According to the " requirements on higher e ducational institutes advisors", advisors are the organizers, the implementers, and the instructors of the daily education on students and can usually be the coordinators of the precaution and care system.

The records of students who need precau tions. This module mainly documents the specific things the school needs to do on student care in or der to facilitate the $m$ onitoring. For example, 
apart from using computer technology to establish the interactive warning output to give the student feedback, we must also give hard copy to inform the student and his family directly. We can use the way of sending "acad emic warning notice", require that the "notice" be sent with track info, keep records of delivery, and finally record such info into the system.

Parents feedback platform. W e should give the parents the account ID and password of the platform, along with "academic warning notice", so that parents can know the courses their child is studying, the grades, and th e academic completion when entering the platform. The parents can contact the coordinators when having problems.

\section{E. Online Attendance Check System.}

When students got prec autions, the system will automatically display the name of the students with marks to the instructors, and the instructors can give these students more care and attention on their attendance and study. Once the instructors find abnormality, they can contact the coordinators to give first hand precautions.

After establishing the system, users only need to use an internet connected computer to finish the corresponding operations, building an invisible bridge among students, parents, and the school. The specific structure is in figure 1.

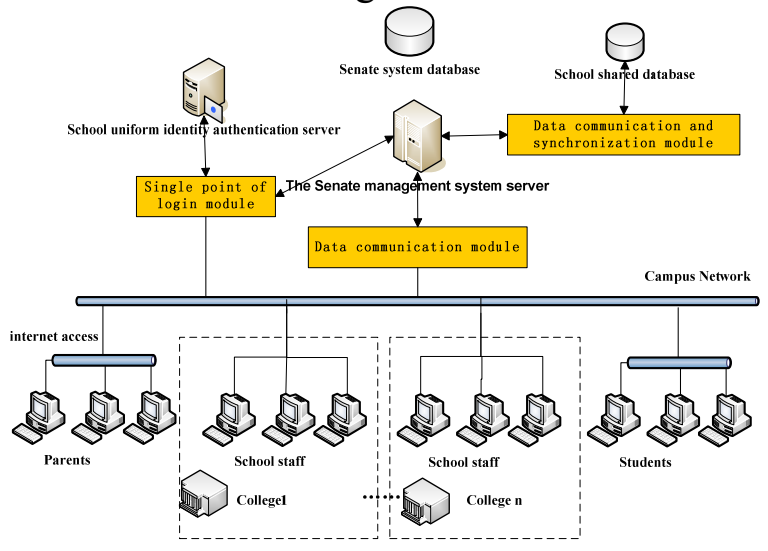

Figure 1 Learning difficulties early warning helping system platform topology diagram

\section{Conclusions}

The purpose of establishing the undergraduate learning difficulties precautions systems is to monitor the students wh en they enter the university, find the students with learn ing difficulties in time, and use strategies to effectively prevent learning difficulties, which is a new task for higher educational institutes using the credit management system. The establishment of a practical an $d$ effective undergraduate learning difficulties precaution system is a po werful tool to $\mathrm{m}$ anage the whole credit based system. We believe that through the cooperation of departments while maintaining the idea of cultivating talented students, we can well perform the care on students with learning difficulties, improve the quality of education, and reach the goal of "no student behind".

\section{References}

[1] Wei Min, training mode, education and vocational college students with learning difficulties to the implementation of the "process management", 2009 (20):37-39 in chinese

[2] Chen Han to bowl lin, conceived to explore a nd examine several problems exist in the study of domestic learning difficulties, Mianyang Normal University, 2005 (6) :75-79, in chinese

[3] Wang Zihua Luo Baoqing genera tion of college stu dents with learning difficulties and early warning mechanism to build, the People's Forum, 2011 (3) :172-173 in chinese

[4] Xue Song, the college learning difficulti es generated thinking, young people and helping strategies research (Science and Culture) 436-438 in chinese

[5] Sun Huaining, based on the campus network of students learning research and design of $t$ he early warning system model, Technology Square 2011:35-37 in chinese 